\title{
A Critical Examination of the Practical Implications Derived from the Food Addiction Concept
}

\author{
Adrian Meule ${ }^{1,2}$
}

Published online: 31 January 2019

(C) The Author(s) 2019

\begin{abstract}
Purpose of Review Adopting an addiction perspective on eating disorders and obesity may have practical implications for diagnostic classification, prevention, and treatment of these disorders. The present article critically examines these implications derived from the food addiction concept.

Recent Findings Introducing food addiction as a new disorder in diagnostic classification system seems redundant as most individuals with an addiction-like eating behavior are already covered by established eating disorder diagnoses. Food addiction may be a useful metaphor in the treatment of binge eating, but would be inappropriate for the majority of obese individuals. Implying an addiction to certain foods is not necessary when applying certain approaches inspired by the addiction field for prevention and treatment of obesity. The usefulness of abstinence models in the treatment of eating disorders and obesity needs to be rigorously tested in future studies.

Summary Some practical implications derived from the food addiction concept provide promising avenues for future research (e.g., using an addiction framework in the treatment of binge eating or applying abstinence models). For others, however, the necessity of implying an addiction to some foods needs to be scrutinized.
\end{abstract}

Keywords Obesity $\cdot$ Eating disorders $\cdot$ Binge eating $\cdot$ Substance use disorders $\cdot$ Prevention $\cdot$ Treatment

\section{Introduction}

Throughout the past century and in recent years, researchers and clinicians have lively debated whether people can become addicted to certain foods [1]. The current state of affairs can be summarized by distinguishing three prevailing views:

(1) Certain foods - usually high-caloric and highly processed foods that contain a large amount of carbohydrates and/or fat - have an addictive potential. Therefore, so-called food addiction represents a substance use disorder [2-4].

(2) Other substances of abuse contain a clear addictive agent (e.g., ethanol in alcoholic beverages, nicotine in tobacco,

This article is part of the Topical Collection on Psychological Issues

Adrian Meule

adrian.meule@sbg.ac.at

1 Department of Psychology, University of Salzburg, Hellbrunner Straße 34, 5020 Salzburg, Austria

2 Center for Cognitive Neuroscience, University of Salzburg, Salzburg, Austria tetrahydrocannabinol in marijuana), but such a specific, addictive substance has not been identified in foods. Therefore, so-called eating addiction represents a nonsubstance-related, behavioral addiction $[5,6]$.

(3) Neither food nor eating addiction represent valid concepts and - even if they are - they are not necessary [7-9].

Most writings on this topic clearly take up one of the three positions and, thus, it appears that this debate cannot be resolved anytime soon. In line with this, Lacroix and colleagues [10] have recently noted that "the topic of addictive-like eating has evoked polarized positions [and] interpretation of the existing evidence regarding addictive-like eating appears to be driven in part by one's a priori views" (p. 291). One of few other recent examples that provide a more balanced discussion and suggests tangible future directions is an article by Fletcher and Kenny [11•].

Whether agreeing that the food addiction concept is valid or not, it seems widely accepted that adopting an addiction perspective on food and eating has practical implications for the prevention and treatment of eating disorders and obesity. Yet, what these actually are exactly is often not explicitly 
spelled out [12] or they are rarely scrutinized dispassionately [10]. Therefore, the present article provides a brief overview of some implications suggested in the literature and aims to evaluate the appropriateness of these suggestions.

\section{Diagnostic Classification Systems}

It stands to reason that if the food or eating addiction concept is accepted as valid, this would imply that food or eating addiction may need to be included as a new addictive disorder in diagnostic classification systems such as the substancerelated and addictive disorder section in the fifth revision of the Diagnostic and Statistical Manual of Mental Disorders (DSM-5). However, as has been discussed previously [9, 13], this may be unwarranted if food or eating addiction is not sufficiently distinct from existing diagnostic entities.

Addiction-like eating behavior strongly overlaps with binge eating as displayed by individuals with bulimia nervosa (BN) and binge eating disorder (BED). In a seminal study by Cassin and von Ranson [14], 92\% of individuals with BED also met substance dependence criteria that referred to binge eating instead of substance in a structured clinical interview. When examining findings with the Yale Food Addiction Scale (YFAS) [15] and YFAS 2.0 [16॰], prevalence rates varied largely across studies with approximately $40-80 \%$ of individuals with BED classified as food addicted [17-20]. In individuals with $\mathrm{BN}$, more than $80 \%$ received a food addiction classification across several studies [19-22].

Although these findings indicate a large overlap between food addiction and binge eating-related disorders, there are of course individuals that show addiction-like eating but do not receive a BN or BED diagnosis. In a study by Ivezaj and colleagues [23•], for example, $19 \%$ of overweight and obese participants were classified as food addicted according to the YFAS, but did not meet criteria for BED. This implies that there may be indeed a subgroup of overweight and obese individuals that show a clinically significant, disordered eating behavior, but do not receive an established eating disorder diagnosis and, thus, may not receive proper treatment. However, a closer inspection reveals that those with food addiction but without BED did indeed exhibit regular binge eating $(M=4.4$ objective binge episodes in the past 28 days), but without fulfilling the full criteria for BED. Moreover, interpretation of the study's findings is limited by the fact that BED classification was based on selfreported binge eating episodes. Thus, it may be that most participants with food addiction but without BED would have received a diagnosis of BED of low frequency and/or limited duration according to DSM-5 in a structured clinical interview. This interpretation is in line with a recent study in which $67 \%$ of individuals with a binge/purge-type other specified feeding or eating disorder diagnosis received a food addiction classification with the YFAS 2.0 [24].
In conclusion, it appears that there are some individuals who show a clinically relevant, addiction-like eating behavior but do not receive an established eating disorder diagnosis. However, the distinctiveness between food addiction and established eating disorder diagnoses needs to be rigorously tested in future studies. When employing structured clinical interviews that cover all eating disorders that are included in DSM-5, it may indeed be that the large majority of individuals who receive a food addiction classification would also receive an established eating disorder diagnosis (including those listed in the other specified feeding or eating disorder section in DSM-5). If this is the case, this would make an inclusion of a possible new "food use disorder" in the substance-related and addictive behavior section redundant.

\section{Obesity Prevention Approaches}

It has been suggested that the food addiction concept has implications for the prevention of obesity [25]. Specifically, if certain foods have an addictive potential, policy regulations may be implemented to limit advertising, increase the price of, or restrict access to such foods, similar to alcohol and tobacco regulations [26]. The downside of such restrictive prevention approaches is that they receive low acceptance by the general public who in turn favor less intrusive approaches (e.g., food labeling or public health campaigns) [27]. This is where the food addiction concept may be helpful because support for obesity policies increases when obesity is attributed to environmental forces and decreases when obesity is viewed as stemming from poor personal choices [26, 28].

A shortcoming of this line of reasoning is that only a minority of obese individuals exhibit an addiction-like eating behavior. Studies using the YFAS or YFAS 2.0 found that between approximately 15 and $25 \%$ of obese individuals can be classified as food addicted [29-31] (although rates can reach up to 50\% in treatment-seeking, extremely obese samples [32]). Accordingly, it has been argued that the food addiction idea is inappropriate for justifying prevention efforts for obesity and that it may even backfire as the food industry may present food addiction as a rare disorder that does not warrant policy changes to influence the general public's eating $[33,34]$.

Moreover, although food policy may be inspired by alcohol and tobacco policies, this does necessitate the presence of food addiction. As an example, taxation of sugar-sweetened beverages has been demanded some time ago [35] and has been implemented in some countries in recent years. Indeed, taxation of sugary drinks seems to be associated with a reduction of sugary drink consumption [36]. This may contribute to obesity prevention as replacing sugary drinks with non-caloric, sweetened drinks reduces energy intake and, subsequently, facilitates weight loss [37]. This is because sugary drinks contain "empty calories", that is, the energy contained in these 
drinks is not satiating. Specifically, people do not compensate the calories contained in beverages by eating less, but consume just as much food irrespective of the caloric content of the beverages $[38,39]$. Thus, although people eat the same amount of food, those who consume caloric soft drinks consume more calories.

In conclusion, effective obesity prevention approaches may, of course, be inspired by alcohol and tobacco prevention and the food addiction concept may help increase acceptance of such actions in the general public. However, the success of such approaches does not depend on whether people are addicted to food or not. Therefore, it seems unnecessary to invoke an addiction to food (or caloric beverages) to implement promising obesity prevention strategies derived from the addiction field.

\section{Treatment Implications}

Several implications of the food addiction concept for the treatment of eating disorders and obesity have been proposed in the literature. These include suggestions for possible new pharmacological approaches, which have been comprehensively discussed elsewhere [40]. In this article, the focus will be on providing an addiction framework for psychoeducation, psychotherapeutic and other techniques, and abstinence models.

\section{Psychoeducation}

Providing an addiction framework in therapy may reduce perceptions of personal failure. As the large majority of individuals with binge eating-related eating disorders displays an addiction-like eating behavior, this may resonate well with most patients. In patients with $\mathrm{BN}$, for example, it has been reported that using addiction as a treatment metaphor can be helpful to motivate change [41, 42]. For most obese persons, however, providing an addiction explanation in therapy may be inappropriate as only a minority of individuals with obesity displays an addiction-like eating behavior. Similarly, while some evidence suggests that the food addiction concept reduces external stigma and self-blame, it may adversely affect self-efficacy and distract attention away from the significant role of exercise for weight regulation and health [33, 43].

\section{Psychotherapeutic and Other Techniques}

A range of treatment elements have been proposed to be implicated by the food addiction concept, which include acceptanceand mindfulness-based techniques for managing food cravings, cue exposure and response prevention, promoting emotion regulation skills, and motivational interviewing [44, 45]. Besides these techniques, there are numerous contemporary approaches that have been examined for reducing craving and consumption in both the food and substance use domain such as non-invasive brain stimulation, bio-/neurofeedback, cognitive bias modification, and executive function trainings (Table 1).

Across different substances (including food), the experience of craving and its cognitive and neural mechanisms are largely similar [59, 64, 65]. Accordingly, interventional strategies that successfully reduce craving for and consumption of alcohol, tobacco, etc. can likely be applied to reduce craving for and consumption of food as well (and vice versa; e.g., [66]). However, this does not require the presence of food addiction. In fact, while the techniques summarized in Table 1 have been tested in clinical samples (e.g., in individuals with BN, BED, or obesity) on the one hand, they have also been applied successfully for reducing food craving and consumption in non-clinical samples (i.e., usually healthy, young, female students) on the other. Thus, it seems that while food-related interventions can, of course, be inspired from the addiction field, such techniques can successfully reduce food craving and consumption without assuming that individuals are addicted to food.

\section{Abstinence Models}

The primary goal of substance use disorder treatment is abstinence, at least for a period of time [67]. Therefore, adopting an addiction perspective on food and eating suggests that those with an addiction-like eating behavior may be best advised to similarly abstain from eating certain foods completely. In fact, such abstinence models have already been discussed decades ago for the treatment of $\mathrm{BN}[68]$ and abstinence is advocated by self-help groups such as Overeaters Anonymous [69, 70]. The definition of abstinence in relation to food is not uniform and may refer to avoiding specific foods or to avoiding specific food ingredients. Thus, abstinence in relation to food may not be accurate from a nutritional or neurochemical point of view. For example, individuals who try to avoid eating sugar may still (inadvertently) consume some foods that contain sugar or, at least, other forms of carbohydrates. Nevertheless, individuals struggling with overeating report that applying an abstinence model helped them to control their eating $[69,70]$.

Although these promising, anecdotal reports exist, abstinence models contrast current practice in cognitivebehavioral therapy. Specifically, cognitive-behavioral therapy aims at reducing dysfunctional dieting in favor of regular eating with flexible and moderate food consumption with no forbidden foods. Thus, it has been argued that abstinence models may be ineffective or-as they encourage dietary restriction - may even be hazardous, particularly in individuals with BN and BED [71]. Indeed, there is experimental evidence that a selective food deprivation increases craving for the avoided foods in vulnerable individuals. For example, when trait chocolate cravers (who had normal weight) were instructed to refrain from eating chocolate-containing foods (but to maintain regular consumption of all other foods), they reported more intense chocolate craving after 2 weeks [72]. 
Table 1 Some examples of intervention approaches that have been applied for reducing craving for and consumption of both food and addictive substances

\begin{tabular}{lll}
\hline General area & Specific technique & References \\
\hline Brain stimulation & Transcranial direct current simulation & {$[46,47]$} \\
& Repetitive transcranial magnetic stimulation & {$[46-48]$} \\
Bio-/neurofeedback & Heart rate variability biofeedback & {$[49]$} \\
& Electroencephalography neurofeedback & {$[50]$} \\
& Functional magnetic resonance imaging & {$[50]$} \\
Cognitive bias modification, executive & neurofeedback & {$[51]$} \\
function training & Attentional bias modification & {$[52]$} \\
& Approach bias modification & {$[53,54]$} \\
& Motor response inhibition training & {$[55,56]$} \\
Other techniques & Working memory training & {$[57]$} \\
& Mindfulness-/acceptance-based strategies & {$[58]$} \\
& Ecological momentary intervention & {$[59]$} \\
& Working memory load/interference & {$[60,61]$} \\
& Cue exposure and response prevention & {$[62,63]$} \\
\hline
\end{tabular}

When examining the effects of weight-loss interventions in obesity, however, results point in another direction: food cravings tend to decrease during energy-restricting diets [73, 74]. In fact, it seems that this decrease in cravings is selective for the types of food avoided: cravings for high-carbohydrate foods selectively decreased during a low-carbohydrate diet while cravings for fatty foods decreased during a low-fat diet [75]. Thus, abstinence models may not be as harmful as some propose but may even be advantageous to other dieting strategies. In contrast to popular belief, rapid weight loss does not lead to greater weight regain. In fact, larger initial weight loss during energy-restricting diets seems to be associated with better long-term outcomes [76]. Thus, avoiding certain energy-dense foods completely may help obese individuals to lose more weight faster, which may relate to better longterm weight maintenance even when they follow this diet only temporarily (that is, without requiring life-long "abstinence").

Rigid dietary control (e.g., completely avoiding certain foods) is usually considered a dysfunctional dieting strategy and, indeed, it relates to higher body mass index crosssectionally [77]. Yet, the causal direction of this relationship needs to be scrutinized. In a recent prospective study, for example, Morin and colleagues [78] experimentally induced cognitive dietary restraint and did not find any adverse impact on food cravings and body weight compared to a control condition. Moreover, it has also been found that the effects of rigid dietary control on food cravings and body weight are attenuated by higher flexible control [77]. Therefore, dietary restraint does not necessarily have to be dysfunctional as long as flexible elements are added. This is in line with a food addiction model of binge eating behavior, which was recently developed by Treasure and colleagues [79•]. While this model recommends to avoid and abstain from certain foods (e.g., foods with a high glycemic index) rather than encouraging an absolute "no dieting approach", it also suggests to discourage individuals from restricting healthy foods to prevent them from reaching a state of semi-starvation.

In conclusion, while contemporary cognitive-behavioral therapy encourages flexible eating with no forbidden foods, the food addiction concept implies that abstinence (i.e., avoiding certain foods) may be a helpful treatment element for individuals with addiction-like eating behavior (e.g., those with binge eating). While such abstinence models are already applied in self-help groups such as Overeaters Anonymous, little is known about the long-term success (and possible adverse effects) of such a strategy. Vidmar and colleagues [80•] recently examined an addiction model-based weight loss intervention in obese adolescents, which included abstaining from "problem foods". While weight loss was comparable to a standard weight loss intervention control group, the "abstinence" group had higher retention rates. More of such studies - and preferably randomized controlled trials that directly compare the two approaches - are desperately needed so that the usefulness of each approach can be evaluated properly.

\section{Conclusions}

Answering the question whether food addiction "is real" crucially depends on how researchers define addiction in general and food addiction in particular. Thus, the food vs. eating vs. not-an-addiction debate will not be resolved anytime soon. When accepting the approach of translating the diagnostic criteria of substance use disorders to food and eating (as is done for the YFAS) as an appropriate procedure for the evaluation of the food addiction concept, many individuals with binge eating — particularly those with $\mathrm{BN}$ - show an eating behavior that resembles an addictive behavior. Accordingly, 
incorporating an addiction framework in the treatment of such individuals may be useful. Whether using an abstinence model (i.e., not eating certain foods) as part of such an addiction framework produces better outcomes (i.e., symptom reduction in eating disorders or weight loss in obesity) than using a flexible model (i.e., that there should be no forbidden foods) - as is done in state-of-the-art cognitive-behavioral therapy — needs to be rigorously tested.

Despite these possibly fruitful implications of the food addiction concept, it seems unnecessary to include food addiction as a new substance use disorder in future diagnostic classification systems because of its large overlap with existing diagnostic entities. As only few obese individuals without binge eating show an addiction-like eating behavior, providing an addiction perspective on eating will likely be inappropriate for the majority of obese persons. Finally, to implement obesity prevention approaches or certain treatment elements inspired by the addiction field does not require that obese people are designated as food addicted. Thus, although an addiction perspective resonates well with many patients with eating disorders and obesity, the necessity and appropriateness of some practical implications derived from the food addiction concept need to be critically evaluated.

Funding Information Open access funding provided by Paris Lodron University of Salzburg.

\section{Compliance with Ethical Standards}

Conflict of Interest Adrian Meule declares that he has no conflict of interest.

Human and Animal Rights and Informed Consent This article does not contain any studies with human or animal subjects performed by any of the authors.

Open Access This article is distributed under the terms of the Creative Commons Attribution 4.0 International License (http:// creativecommons.org/licenses/by/4.0/), which permits unrestricted use, distribution, and reproduction in any medium, provided you give appropriate credit to the original author(s) and the source, provide a link to the Creative Commons license, and indicate if changes were made.

Publisher's Note Springer Nature remains neutral with regard to jurisdictional claims in published maps and institutional affiliations.

\section{References}

Papers of particular interest, published recently, have been highlighted as:

- Of importance

1. Meule A. A history of "food addiction". In: Cottone P, Sabino V, Moore C, Koob G, editors. Food addiction and compulsive eating behavior. Philadelphia: Elsevier; 2019.

2. Ifland J, Preuss HG, Marcus MT, Rourke KM, Taylor W, Wright HT. Clearing the confusion around processed food addiction. J Am
Coll Nutr. 2015;34:240-3. https://doi.org/10.1080/07315724.2015. 1022466.

3. Schulte EM, Potenza MN, Gearhardt AN. A commentary on the "eating addiction" versus "food addiction" perspectives on addictive-like food consumption. Appetite. 2017;115:9-15. https://doi.org/10.1016/j.appet.2016.10.033.

4. Schulte EM, Potenza MN, Gearhardt AN. Specific theoretical considerations and future research directions for evaluating addictivelike eating as a substance-based, food addiction: comment on Lacroix et al. (2018). Appetite. 2018;130:293-5. https://doi.org/ 10.1016/j.appet.2018.06.026.

5. Hebebrand J, Albayrak Ö, Adan R, Antel J, Dieguez C, de Jong J, et al. "Eating addiction", rather than "food addiction", better captures addictive-like eating behavior. Neurosci Biobehav Rev. 2014;47:295306. https://doi.org/10.1016/j.neubiorev.2014.08.016.

6. Ruddock H, Christiansen P, Halford J, Hardman C. The development and validation of the addiction-like eating behaviour scale. Int J Obes. 2017;41:1710-7. https://doi.org/10.1038/ijo.2017.158.

7. Finlayson G. Food addiction and obesity: unnecessary medicalization of hedonic overeating. Nat Rev Endocrinol. 2017;13:493-8. https://doi.org/10.1038/nrendo.2017.61.

8. Rogers PJ. Food and drug addictions: similarities and differences. Pharmacol Biochem Behav. 2017;153:182-90. https://doi.org/10. 1016/j.pbb.2017.01.001.

9. Long CG, Blundell JE, Finlayson G. A systematic review of the application and correlates of YFAS-diagnosed 'food addiction' in humans: are eating-related 'addictions' a cause for concern or empty concepts? Obes Facts. 2015;8:386-401. https://doi.org/10.1159/ 000442403.

10. Lacroix E, Tavares H, von Ranson KM. Moving beyond the "eating addiction" versus "food addiction" debate: comment on Schulte et al. (2017). Appetite. 2018;130:286-92. https://doi.org/10.1016/ j.appet.2018.06.025.

11. Fletcher PC, Kenny PJ. Food addiction: a valid concept? Neuropsychopharmacology. 2018;43:2506-13. https://doi.org/10. 1038/s41386-018-0203-9 This article discusses arguments against and in favor of the food addiction concept in terms of behavioral consumption patterns and neural mechanisms in an open-minded manner.

12. Naish KR, MacKillop J, Balodis IM. The concept of food addiction: a review of the current evidence. Curr Behav Neurosci Rep. 2019;5: 281-94. https://doi.org/10.1007/s40473-018-0169-2.

13. Vainik U, Meule A. Jangle fallacy epidemic in obesity research: a comment on Ruddock et al. (2017). Int J Obes. 2018;42:585-6. https://doi.org/10.1038/ijo.2017.264.

14. Cassin SE, von Ranson KM. Is binge eating experienced as an addiction? Appetite. 2007;49:687-90. https://doi.org/10.1016/j. appet.2007.06.012.

15. Gearhardt AN, Corbin WR, Brownell KD. Preliminary validation of the Yale Food Addiction Scale. Appetite. 2009;52:430-6. https:// doi.org/10.1016/j.appet.2008.12.003.

16. Gearhardt AN, Corbin WR, Brownell KD. Development of the Yale Food Addiction Scale Version 2.0. Psychol Addict Behav. 2016;30:113-21. https://doi.org/10.1037/adb0000136 This article presents the development of the YFAS 2.0, which is based on food-related equivalents to the diagnostic criteria for substance use disorder in DSM-5 and is the most widely used measure for the assessment of addiction-like eating to date.

17. Gearhardt AN, White MA, Masheb RM, Grilo CM. An examination of food addiction in a racially diverse sample of obese patients with binge eating disorder in primary care settings. Compr Psychiatry. 2013;54:500-5. https://doi.org/10.1016/j.comppsych. 2012.12.009.

18. Gearhardt AN, White MA, Masheb RM, Morgan PT, Crosby RD, Grilo CM. An examination of the food addiction construct in obese 
patients with binge eating disorder. Int J Eat Disord. 2012;45:65763. https://doi.org/10.1002/eat.20957.

19. Granero R, Hilker I, Agüera Z, Jiménez-Murcia S, Sauchelli S, Islam MA, et al. Food addiction in a Spanish sample of eating disorders: DSM-5 diagnostic subtype differentiation and validation data. Eur Eat Disord Rev. 2014;22:389-96. https://doi.org/10.1002/ erv.2311.

20. Granero R, Jiménez-Murcia S, Gearhardt AN, Aguera Z, Aymamí $\mathrm{N}$, Gómez-Peña $\mathrm{M}$, et al. Validation of the Spanish version of the Yale Food Addiction Scale 2.0 (YFAS 2.0) and clinical correlates in a sample of eating disorder, gambling disorder and healthy control participants. Front Psych. 2018;9(208):1-11. https://doi.org/10. 3389/fpsyt.2018.00208.

21. de Vries S-K, Meule A. Food addiction and bulimia nervosa: New data based on the Yale Food Addiction Scale 2.0. Eur Eat Disord Rev. 2016;24:518-22. https://doi.org/10.1002/erv.2470.

22. Meule A, Rezori V, Blechert J. Food addiction and bulimia nervosa. Eur Eat Disord Rev. 2014;22:331-7. https://doi.org/10.1002/erv.2306.

23. Ivezaj V, White MA, Grilo CM. Examining binge-eating disorder and food addiction in adults with overweight and obesity. Obesity. 2016;24:2064-9. https://doi.org/10.1002/oby.21607 This study examined the relationships and correlates of binge eating and food addiction as measured with the YFAS in a large sample of individuals with overweight and obesity.

24. Carlson L, Steward T, Agüera Z, Mestre-Bach G, Magaña P, Granero R, et al. Associations of food addiction and nonsuicidal self-injury among women with an eating disorder: a common strategy for regulating emotions? Eur Eat Disord Rev. 2019;26:629-37. https://doi.org/10.1002/erv.2646.

25. Gearhardt AN, Brownell KD. Can food and addiction change the game? Biol Psychiatry. 2013;73:802-3. https://doi.org/10.1016/j. biopsych.2012.07.024.

26. Pomeranz JL, Roberto CA. The impact of 'food addiction' on food policy. Curr Addict Rep. 2014;1:102-8. https://doi.org/10.1007/ s40429-014-0015-x.

27. Hagmann D, Siegrist M, Hartmann C. Taxes, labels, or nudges? Public acceptance of various interventions designed to reduce sugar intake. Food Policy. 2018;79:156-65. https://doi.org/10.1016/j. foodpol.2018.06.008.

28. Moran A, Musicus A, Soo J, Gearhardt AN, Gollust SE, Roberto CA. Believing that certain foods are addictive is associated with support for obesity-related public policies. Prev Med. 2016;90: 39-46. https://doi.org/10.1016/j.ypmed.2016.06.018.

29. Meule A, Gearhardt AN. Five years of the Yale Food Addiction Scale: taking stock and moving forward. Curr Addict Rep. 2014;1: 193-205. https://doi.org/10.1007/s40429-014-0021-z.

30. Steward T, Mestre-Bach G, Vintró-Alcaraz C, Lozano-Madrid M, Agüera Z, Fernández-Formoso JA, et al. Food addiction and impaired executive functions in women with obesity. Eur Eat Disord Rev. 2019;26:574-84. https://doi.org/10.1002/erv.2636.

31. Hauck C, Weiß A, Schulte EM, Meule A, Ellrott T. Prevalence of 'food addiction' as measured with the Yale Food Addiction Scale 2.0 in a representative German sample and its association with sex, age and weight categories. Obes Facts. 2017;10:12-24. https://doi. org/10.1159/000456013.

32. Meule A, Müller A, Gearhardt AN, Blechert J. German version of the Yale Food Addiction Scale 2.0: prevalence and correlates of 'food addiction' in students and obese individuals. Appetite. 2017;115:54-61. https://doi.org/10.1016/j.appet.2016.10.003.

33. Lee NM, Carter A, Owen N, Hall WD. The neurobiology of overeating. EMBO Rep. 2012;13:785-90. https://doi.org/10.1038/ embor.2012.115.

34. Hebebrand J. Obesity prevention: moving beyond the food addiction debate. J Neuroendocrinol. 2015;27:737-8. https://doi.org/10. 1111/jne.12304.
35. Brownell KD, Frieden TR. Ounces of prevention - the public policy case for taxes on sugared beverages. N Engl J Med. 2009;360:1805-8. https://doi.org/10.1056/NEJMp0902392.

36. Frew E, Ng SW, Coast J, Hollingsworth B, Smith R. How can economics help tackle obesity? Obesity. 2018;26:1112-3. https:// doi.org/10.1002/oby.22211

37. Rogers PJ, Hogenkamp PS, de Graaf C, Higgs S, Lluch A, Ness $\mathrm{AR}$, et al. Does low-energy sweetener consumption affect energy intake and body weight? A systematic review, including meta-analyses, of the evidence from human and animal studies. Int J Obes. 2015;40:381-94. https://doi.org/10.1038/ijo.2015.177.

38. Anton SD, Martin CK, Han H, Coulon S, Cefalu WT, Geiselman P, et al. Effects of stevia, aspartame, and sucrose on food intake, satiety, and postprandial glucose and insulin levels. Appetite. 2010;55: 37-43. https://doi.org/10.1016/j.appet.2010.03.009.

39. Panahi S, El Khoury D, Luhovyy BL, Goff HD, Anderson GH. Caloric beverages consumed freely at meal-time add calories to an ad libitum meal. Appetite. 2013;65:75-82. https://doi.org/10. 1016/j.appet.2013.01.023.

40. Bocarsly ME. Pharmacological interventions for obesity: current and future targets. Curr Addict Rep. 2018;5:202-11. https://doi. org/10.1007/s40429-018-0204-0.

41. Slive A, Young F. Bulimia as substance abuse: a metaphor for strategic treatment. J Strategic Systemic Ther. 1986;5:71-84. https://doi.org/10.1521/jsst.1986.5.3.71.

42. Cosci F. Bulimia nervosa treated with an adapted version of Carroll's cognitive-behavioral approach for treatment of cocaine addiction. J Neuropsychiatry Clin Neurosci. 2014;26:E28-E9. https://doi.org/10.1176/appi.neuropsych.13110330.

43. Reid J, O'Brien KS, Puhl R, Hardman CA, Carter A. Food addiction and its potential links with weight stigma. Curr Addict Rep. 2018;5:192-201. https://doi.org/10.1007/s40429-018-0205-z.

44. Grosshans M, Loeber S, Kiefer F. Implications from addiction research towards the understanding and treatment of obesity. Addict Biol. 2011;16:189-98. https://doi.org/10.1111/j.1369-1600.2010. 00300.x

45. Davis C, Carter JC. If certain foods are addictive, how might this change the treatment of compulsive overeating and obesity? Curr Addict Rep. 2014;1:89-95. https://doi.org/10.1007/s40429-0140013-z.

46. Jansen JM, Daams JG, Koeter MWJ, Veltman DJ, van den Brink W, Goudriaan AE. Effects of non-invasive neurostimulation on craving: a meta-analysis. Neurosci Biobehav Rev. 2013;37:2472-80. https://doi.org/10.1016/j.neubiorev.2013.07.009.

47. Lowe CJ, Vincent C, Hall PA. Effects of noninvasive brain stimulation on food cravings and consumption: a meta-analytic review. Psychosom Med. 2017;79:2-13. https://doi.org/10.1097/psy. 0000000000000368.

48. Grall-Bronnec M, Sauvaget A. The use of repetitive transcranial magnetic stimulation for modulating craving and addictive behaviours: a critical literature review of efficacy, technical and methodological considerations. Neurosci Biobehav Rev. 2014;47:592613. https://doi.org/10.1016/j.neubiorev.2014.10.013.

49. Alayan N, Eller L, Bates ME, Carmody DP. Current evidence on heart rate variability biofeedback as a complementary anticraving intervention. J Altern Complement Med. 2018;24:1039-50. https:// doi.org/10.1089/acm.2018.0019.

50. Schmidt J, Kärgel C, Opwis M. Neurofeedback in substance use and overeating: current applications and future directions. Curr Addict Rep. 2017;4:116-31. https://doi.org/10.1007/s40429-017-0137-z.

51. Field M, Werthmann J, Franken I, Hofmann W, Hogarth L, Roefs A. The role of attentional bias in obesity and addiction. Health Psychol. 2016;35:767-80. https://doi.org/10.1037/hea0000405.

52. Kakoschke N, Kemps E, Tiggemann M. Approach bias modification training and consumption: a review of the literature. Addict Behav. 2017;64:21-8. https://doi.org/10.1016/j.addbeh.2016.08.007. 
53. Houben $\mathrm{K}$, Havermans RC, Nederkoorn C, Jansen A. Beer à no-go: learning to stop responding to alcohol cues reduces alcohol intake via reduced affective associations rather than increased response inhibition. Addiction. 2012;107:1280-7. https://doi.org/10.1111/j. 1360-0443.2012.03827.x.

54. Veling H, Lawrence NS, Chen Z, van Koningsbruggen GM, Holland RW. What is trained during food go/no-go training? A review focusing on mechanisms and a research agenda. Curr Addict Rep. 2017;4:35-41. https://doi.org/10.1007/s40429-0170131-5.

55. Houben K, Dassen FCM, Jansen A. Taking control: working memory training in overweight individuals increases self-regulation of food intake. Appetite. 2016;105:567-74. https://doi.org/10.1016/j. appet.2016.06.029.

56. Houben K, Wiers RW, Jansen A. Getting a grip on drinking behavior: training working memory to reduce alcohol abuse. Psychol Sci. 2011;22:968-75. https://doi.org/10.1177/0956797611412392.

57. Tapper K. Mindfulness and craving: effects and mechanisms. Clin Psychol Rev. 2018;59:101-17. https://doi.org/10.1016/j.cpr.2017. 11.003.

58. Heron KE, Smyth JM. Ecological momentary interventions: incorporating mobile technology into psychosocial and health behaviour treatments. Br J Health Psychol. 2010;15:1-39. https://doi.org/10. 1348/135910709X466063.

59. May J, Kavanagh DJ, Andrade J. The elaborated intrusion theory of desire: a 10-year retrospective and implications for addiction treatments. Addict Behav. 2015;44:29-34. https://doi.org/10.1016/j. addbeh.2014.09.016.

60. Mellentin AI, Skøt L, Nielsen B, Schippers GM, Nielsen AS, Stenager E, et al. Cue exposure therapy for the treatment of alcohol use disorders: a meta-analytic review. Clin Psychol Rev. 2017;57: 195-207. https://doi.org/10.1016/j.cpr.2017.07.006.

61. van den Akker K, Schyns G, Jansen A. Learned overeating: applying principles of pavlovian conditioning to explain and treat overeating. Curr Addict Rep. 2018;5:223-31. https://doi.org/10.1007/ s40429-018-0207-x.

62. Boswell RG, Sun W, Suzuki S, Kober H. Training in cognitive strategies reduces eating and improves food choice. Proc Natl Acad Sci. 2019;115:E11238-47. https://doi.org/10.1073/pnas. 1717092115.

63. Kober H, Kross EF, Mischel W, Hart CL, Ochsner KN. Regulation of craving by cognitive strategies in cigarette smokers. Drug Alcohol Depend. 2010;106:52-5. https://doi.org/10.1016/j. drugalcdep.2009.07.017.

64. May J, Andrade J, Kavanagh DJ, Feeney GFX, Gullo MJ, Statham DJ, et al. The craving experience questionnaire: a brief, theorybased measure of consummatory desire and craving. Addiction. 2014;109:728-35. https://doi.org/10.1111/add.12472.

65. Hone-Blanchet A, Fecteau S. Overlap of food addiction and substance use disorders definitions: analysis of animal and human studies. Neuropharmacology. 2014;85:81-90. https://doi.org/10.1016/j. neuropharm.2014.05.019.

66. Hone-Blanchet A, Ciraulo DA, Pascual-Leone A, Fecteau S. Noninvasive brain stimulation to suppress craving in substance use disorders: review of human evidence and methodological considerations for future work. Neurosci Biobehav Rev. 2015;59:184 200. https://doi.org/10.1016/j.neubiorev.2015.10.001.
67. Marlatt GA. The controlled-drinking controversy: a commentary. Am Psychol. 1983;38:1097-110. https://doi.org/10.1037/0003066X.38.10.1097.

68. Bemis KM. "abstinence" and "nonabstinence" models for the treatment of bulimia. Int J Eat Disord. 1985;4:407-37. https://doi.org/10.1002/ 1098-108X(198511)4:4<407::AID-EAT2260040404>3.0.CO;2-P.

69. Rodríguez-Martín BC, Gallego-Arjiz B. Overeaters anonymous: a mutual-help fellowship for food addiction recovery. Front Psychol. 2018;9(1491):1-5. https://doi.org/10.3389/fpsyg.2018.01491.

70. Russell-Mayhew S, von Ranson KM, Masson PC. How does overeaters anonymous help its members? A qualitative analysis. Eur Eat Disord Rev. 2010;18:33-42. https://doi.org/10.1002/erv.966.

71. Wilson GT. Eating disorders, obesity and addiction. Eur Eat Disord Rev. 2010;18:341-51. https://doi.org/10.1002/erv.1048.

72. Richard A, Meule A, Friese M, Blechert J. Effects of chocolate deprivation on implicit and explicit evaluation of chocolate in high and low trait chocolate cravers. Front Psychol. 2017;8(1591):1-11. https://doi.org/10.3389/fpsyg.2017.01591.

73. Kahathuduwa CN, Binks M, Martin CK, Dawson JA. Extended calorie restriction suppresses overall and specific food cravings: a systematic review and a meta-analysis. Obes Rev. 2017;18:112235. https://doi.org/10.1111/obr.12566.

74. Oustric P, Gibbons C, Beaulieu K, Blundell J, Finlayson G. Changes in food reward during weight management interventions - a systematic review. Obes Rev. 2018;19:1642-58. https://doi.org/ 10.1111/obr.12754.

75. Martin CK, Rosenbaum D, Han H, Geiselman PJ, Wyatt HR, Hill JO, et al. Change in food cravings, food preferences, and appetite during a low-carbohydrate and low-fat diet. Obesity. 2011;19: 1963-70. https://doi.org/10.1038/oby.2011.62.

76. Casazza K, Brown A, Astrup A, Bertz F, Baum C, Brown MB, et al. Weighing the evidence of common beliefs in obesity research. Crit Rev Food Sci Nutr. 2015;55:2014-53. https://doi.org/10.1080/ 10408398.2014.922044.

77. Meule A. Interactive effects between flexible and rigid control of eating behavior on body weight: a moderated serial multiple mediation model. Health Psychol Rep. 2017;5:314-22. https://doi.org/ 10.5114/hpr.2017.70206.

78. Morin I, Bégin C, Maltais-Giguère J, Bédard A, Tchernof A, Lemieux S. Impact of experimentally induced cognitive dietary restraint on eating behavior traits, appetite sensations, and markers of stress during energy restriction in overweight/obese women. J Obes. 2018;2018(4259389):1-12. https://doi.org/10.1155/2018/ 4259389.

79. Treasure J, Leslie M, Chami R, Fernández-Aranda F. Are trans diagnostic models of eating disorders fit for purpose? A consideration of the evidence for food addiction. Eur Eat Disord Rev. 2018;26:83-91. https://doi.org/10.1002/erv.2578 This article presents a food addiction model of binge eating, including implications for treatment.

80. Vidmar AP, Pretlow R, Borzutzky C, Wee CP, Fox DS, Fink C, et al. An addiction model-based mobile health weight loss intervention in adolescents with obesity. Pediatr Obes. 2019;14:e12464. $\mathrm{https}: / /$ doi.org/10.1111/ijpo.12464. This is the first study that compared an addiction model-based weight-loss intervention-which included abstinence from certain foods-with a standard weight-loss intervention regarding weight loss and treatment adherence in obese adolescents. 